\title{
APLIKASI KARBON AKTIF KAYU ULIN SEBAGAI ADSORBEN DALAM MENURUNKAN KANDUNGAN CHEMICAL OXYGEN DEMAND (COD) PADA AIR SUNGAI
}

APPLICATION OF ULIN WOOD ACTIVATED CARBON AS AN ADSORBENT FOR REMOVING THE CHEMICAL OXYGEN DEMAND (COD) CONTENT IN RIVER WATER

\author{
Herlina Astuti ${ }^{1}$, Rijali Noor ${ }^{1}$, Mahmud $^{1}$ \\ ${ }^{1}$ Program Studi Teknik Lingkungan, Fakultas Teknik, Universitas Lambung Mangkurat, Jl. Jend. A. \\ Yani Km 36, Banjarbaru, Kalimantan Selatan, 70714, Indonesia.
}

Email:1610815220009@mhs.ulm.ac.id

\begin{abstract}
ABSTRAK
Penelitian ini memiliki tujuan dalam mengidentifikasi karakteristik karbon aktif dari kayu ulin dan pengaplikasiannya dalam menurunkan kandungan COD (Chemical Oxygen Demand) air sungai. Penelitian ini dilakukan secara ekperimental di Laboratorium Rekayasa Teknik Lingkungan, Universitas Lambung Mangkurat. Beberapa variabel bebas yang digunakan meliputi $\mathrm{pH}$ (3, 5, 7, dan 9), waktu kontak $(5,10,15,60,120,180$, dan 240 menit), dan dosis adsorben $(0,4 ; 0,6 ; 0,8$ dan 1,0 gr)., sedangkan variabel terikat berupa kandungan COD pada air sungai. Uji karakteristik adsorben karbon aktif kayu ulin, menghasilkan nilai kadar air sebesar $5 \%$, daya serap iodin sebesar 190,350 mg/g, dan kadar abu sebesar 89\%. Kondisi operasi terbaik adsorpsi COD (Chemical Oxygen Demand) pada air sungai terhadap karbon aktif kayu ulin terjadi pada kondisi pH 5 dengan kapasitas adsorpsi 34,73 mg/g dan efesiensi adsorpsi 40\% ; waktu kesetimbangan 120 menit dengan kapasitas adsorpsi 43,41 mg/g dan efesiensi adsorpsi 50\%: dan dosis adsorben sebanyak 1 gram dengan kapasitas adsorpsi 31,25 mg/g dan efesiensi adsorpsi $45 \%$.
\end{abstract}

Kata kunci: Karbon Aktif Kayu Ulin, Adsorpsi, COD, Kapasitas adsorpsi

ABSTRACT

The aims of this study was to identify the characteristics ironwood activated carbon and its application to reduce the COD (Chemical Oxygen Demand) content in river water. This study was conducted experimentally at the Environmental Engineering Laboratory, Lambung Mangkurat University. Several independent variables used were $\mathrm{pH}(3,5,7$, and 9), contact time (5, 10, 15, 60, 120, 180 and 240 minutes), and the adsorbent dose (0.4; 0.6; 0.8 and $1.0 \mathrm{gr}$ ), while the dependent variable was the COD content in river water. The test results of the characteristics of ironwood activated carbon adsorbent, namely water content of 5\%, iodine absorption of $190.350 \mathrm{mg} / \mathrm{g}$, and ash content of $89 \%$. The best operating conditions for COD (Chemical Oxygen Demand) adsorption in river water against ironwood activated carbon occurred at $\mathrm{pH} 5$ with an adsorption capacity of $34,73 \mathrm{mg} / \mathrm{g}$ and an adsorption efficiency of 40\%; equilibrium time for 120 minutes with an adsorption capacity of 43,41 $\mathrm{mg} / \mathrm{g}$ and an adsorption efficiency of 50\%; and the adsorbent dose of 1 gram with an adsorption capacity of $27,78 \mathrm{mg}$ I $g$ and an adsorption efficiency of $40 \%$. 
Keywords: Ulin Wood Activated Carbon, Adsorption, COD, Adsorption capacity

\section{PENDAHULUAN}

Kalimantan memiliki berbagai jenis pohon hutan, salah satunya adalah kayu ulin. Kayu ulin dikenal dengan ketahanan dan keawetan kayu yang sangat baik, sehingga pemanfaatannya memiliki nilai ekonomis yang tinggi. Pemanfaatan karbon aktif dari serbuk gergaji kayu ulin sebagai adsorben telah diteliti oleh Matilda et al. (2016) dan Mirwan et al. (2019). Kayu ulin memiliki makro molekul yang kompleks dengan komposisi selulosa 51\%, pentosin 12,7\%, dan lignin 28,9\% (Badariah, 2013).

Desa Sungai Pinang Lama merupakan salah satu desa di Kecamatan Sungai Tabuk, Kabupaten Banjar, yang memanfaatkan badan air sungai untuk memenuhi kebutuhan sehari-hari seperti mandi, mencuci, kakus, dan bahkan digunakan sebagai air minum dan memasak. Peruntukan Sungai Martapuran juga digunakan sebagai air intake PDAM. Berdasarkan uji pendahuluan yang telah dilakukan, kandungan COD (Chemical Oxygen Demand) air Sungai Martapura sebesar 78,15 mg/L. Kondisi ini berarti sudah melebihi baku mutu peruntukan air kelas I yang ditetapkan oleh Peraturan Gubernur Kalimantan Selatan Nomor 5 Tahun 2007.

COD (Chemical Okygen Demand) merupakan proses penentuan jumlah oksigen yang diperlukan untuk mengoksidasi senyawa organik secara kimia. COD menjadi salah satu parameter yang dapat mendeteksi tingkat pencemaran pada suatu perairan. Kandungan oksigen terlarut (DO) yang rendah dalam air akan memperburuk kondisi pada kehidupan biota air. Semakin rendah oksigen terlarut dapat memunculkan kondisi anaerobic dengan bau busuk dan menyebabkan permasalahan estetika (Ningrum, 2018).

Adsorpsi merupakan proses transfer fasa untuk menghilangkan zat dari fasa fluida (Valand et al., 2019). Hal ini juga dapat dijelaskan dengan adanya proses pengikatan molekul akibat gaya Van Der Waals. Penurunan nilai COD dapat dilakukan melalui proses adsoprsi. Hal tersebut telah diungkapkan melalui beberapa penelitian (Nayl et al., 2017; Rosli et al., 2018; Valand et al., 2019).

Pemanfaatan air Sungai Martapura oleh masyarakat dengan kualitas rendah menjadi hal yang krusial jika terus dikonsumsi. Pengolahan air perlu dilakukan, salah satunya melalui proses adsorpsi dengan karbon aktif dari limbah kayu ulin. Kayu khas Kalimantan tersebut memiliki potensi untuk dimanfaatkan menjadi karbon aktif karena sifat yang dimiliki kayu tersebut dan cukup mudah ditemukan. Latar belakang menjadi dasar penelitian dalam mengidentifikasi karakteristik karbon aktif dari kayu ulin dan pengaplikasiannya untuk menurunkan kandungan COD (Chemical Oxygen Demand) air sungai Martapura.

\section{METODE PENELITIAN}

Penelitian ini memiliki tujuan untuk mengidentifikasi karakteristik adsorben karbon aktif kayu ulin dan kemampuannya dalam menurunkan kandungan COD pada air sungai. Karbon aktif yang digunakan berasal dari limbah kayu ulin yang diambil dari tempat pembuatan meubel di Jalan Puyau Kecamatan Banjarbaru Selatan, Banjarbaru, Kalimantan Selatan. Sampel air sungai diambil dari Sungai Martapura di Jalan Gubernur Sarkawi Km.5,7 Kecamatan Sungai Tabuk, Kabupaten Banjar, tepatnya di Desa Sungai Pinang Lama. Penelitian ini dilakukan secara ekperimental di Laboratorium Rekayasa Teknik 
Lingkungan, Universitas Lambung Mangkurat. Beberapa variabel bebas yang digunakan meliputi pH (3, 5, 7, dan 9), waktu kontak $(5,10,15,60,120,180$, dan 240 menit), dan dosis adsorben $(0,4 ; 0,6 ; 0,8$ dan 1,0 gr)., sedangkan variabel terikat berupa kandungan COD pada air sungai. Pengulangan yang dilakukan tiap perlakuan adalah sebanyak dua kali. Uji kandungan COD dilakukan secara duplo. Rancangan penelitian ini dirincikan pada Tabel 1.

\begin{tabular}{|c|c|c|c|c|}
\hline Percobaan & pH & Waktu Kontak & Dosis & Hasil \\
\hline Menentukan $\mathrm{pH}$ terbaik & $3,5,7$ dan 9 & 240 menit & $0,8 \mathrm{gr} / \mathrm{L}$ & $\mathrm{pH}$ terbaik \\
\hline $\begin{array}{l}\text { Menentukan waktu } \\
\text { kontak setimbang }\end{array}$ & $\mathrm{pH}$ terbaik & $\begin{array}{c}5,10,15,60, \\
120,180, \text { dan } \\
240 \text { menit }\end{array}$ & $0,8 \mathrm{gr} / \mathrm{L}$ & $\begin{array}{c}\text { Waktu kontak } \\
\text { setimbang }\end{array}$ \\
\hline Menentukan dosis terbaik & $\mathrm{pH}$ terbaik & $\begin{array}{c}\text { Waktu kontak } \\
\text { setimbang }\end{array}$ & $\begin{array}{c}0,4 ; 0,6 ; 0,8 \\
\text { dan } 1,0 \mathrm{gr}\end{array}$ & Dosis terbaik \\
\hline
\end{tabular}

Beberapa tahapan yang dilakukan meliputi tahap pendahuluan, tahap persiapan, preparasi karbon aktif, karbonasi dan aktivasi karbon aktif, karakterisasi karbon aktif dan sampel air sungai, serta penentuan $\mathrm{pH}$, waktu kontak, dan dosis terbaik yang menjadi hasil dari penelitian ini. Metode yang digunakan pada pemeriksaan kandungan COD adalah metode titrasi permanganometri. Analisis yang digunakan untuk karakterisasi karbon aktif yaitu kadar air, daya serap iod dan kadar abu.

Tahap pendahuluan dilakukan dengan studi literatur yang berguna sebagai acuan dalam penelitian ini, kemudian melakukan tahap persiapan yang terdiri dari pengumpulan bahan mentah karbon aktif berupa limbah potongan kayu ulin dan pengambilan sampel air sungai. Tahap preparasi berlangsung dengan proses penghilangan gas $\mathrm{O}_{2}$ dengan menginjeksikan gas $\mathrm{N}_{2}$ tanpa tekanan selama 5 menit ke dalam tabung karbonasi yang berisi potongan kayu ulin yan telah disiapkan, kemudian dilanjutkan proses pengembangan struktur rongga pada arang dengan injeksi $\mathrm{N}_{2}$ bertekanan 10 bar selama 40 menit serta melalui proses pirolisis selama 2 jam dengan suhu $200^{\circ} \mathrm{C}$. Proses ini dilanjutkan dengan tahap karbonasi yang dilakukan dengan memasukkan tabung karbonasi ke dalam furnace selama 4 jam bersuhu $400^{\circ} \mathrm{C}$. Proses aktivasi fisika dilakukan setelah karbon kayu ulin diayak 80-100 mesh dan dimasukkan ke dalam furnace bersuhu $650^{\circ} \mathrm{C}$ selama 2 jam. Tahap selanjutnya yaitu pengaplikasian karbon aktif tersebut pada sampel air sungai untuk mengetahui kapasitas dan efesiensi adsorpsi COD air sungai.

\section{HASIL DAN PEMBAHASAN}

Karakteristik karbon aktif kayu ulin yang dilakukan pada penelitian ini adalah daya serap iodin, kadar air, serta kadar abu karbon aktif. Prosedur pengujian berdasarkan SNI 06-3730-1995 dengan ketentuan standar dari tiga parameter tersebut, yaitu daya serap terhadap iodium minimal $750 \mathrm{mg} / \mathrm{g}$, kadar air maksimal untuk serbuk maksimal 15\%, serta kadar abu maksimal 10\%. Hasil uji karakteristik karbon aktif kayu ulin terdapat pada Tabel 2 berikut. 
Tabel 2. Karakteristik karbon aktif kayu ulin

\begin{tabular}{clcc}
\hline No & Karakteristik & $\begin{array}{c}\text { Jumlah } \\
\text { Terkandung }\end{array}$ & Satuan \\
\hline 1 & Daya serap iodin & 190,350 & $\mathrm{mg} / \mathrm{g}$ \\
2 & Kadar air & 5 & $\%$ \\
3 & Kadar abu & 89 & $\%$ \\
\hline
\end{tabular}

Daya serap iodin dari karbon aktif kayu ulin dihasilkan sebesar 190,350 mg/g. Besaran ini masih belum memenuhi persyaratan SNI 06-3730-1995 yang memiliki nilai minimum daya serap iodin sebesar 750 $\mathrm{mg} / \mathrm{g}$. Penyebab hal tersebut dapat dikarenakan pada pengaruh temperatur aktivasi, dan waktu karbonisasi. Bahan dasar karbon aktif yang memiliki persentase burn off tinggi menyebabkan sebagian besar bahan dasar hangus terbakar. Hal tersebut dapat mempengaruhi daya serap iodin karbon aktif (Ibrahim et al., 2015). Kadar air yang dihasilkan karbon aktif kayu ulin sebesar 5\%. Nilai ini telah memenuhi persayratan SNI 06-3730-1995 yang menentukan standar minimum kadar air kurang dari $15 \%$. Nilai kadar air yang rendah diakibatkan oleh temperatur pengeringan tinggi. Kadar air yang rendah berarti menghasilkan pori yang semakin besar, sehingga kemampuan adsorpsi dari karbon aktif lebih besar (Laos et al., 2016). Hasil uji pada kadar abu karbon aktif kayu ulin belum memenuhi SNI 06-37031995, yaitu sebesar 89\%. Kadar abu yang tinggi mengakibatkan penyumbatan pada pori-pori karbon aktif, sehingga terjadi penyempitan pada luas permukaan karbon aktif (Laos and Selan, 2016).

Penelitian ini menggunakan sampel air sungai yang berasal dari Sungai Martapura. Karakteristik awal air sungai yang dapat dilihat pada Tabel 3. Nilai COD Sungai Martapura berdasarkan hasil uji telah melebihi baku mutu air yang telah ditetapkan Peraturan Gubernur Kalimantan Selatan Nomor 5 Tahun 2007 pada peruntukan air kelas I maupun II.

Tabel 3. Hasil Pengujian Awal Kualitas Air Sungai

\begin{tabular}{llcc}
\hline No & Karakteristik & $\begin{array}{c}\text { Jumlah } \\
\text { Terkandung }\end{array}$ & Satuan \\
\hline 1 & COD & 69,45 & $\mathrm{mg} / \mathrm{L}$ \\
2 & $\mathrm{pH}$ & 7 & - \\
3 & Temperatur & 29,4 & ${ }^{\circ} \mathrm{C}$ \\
4 & TDS & 83,5 & $\mathrm{mg} / \mathrm{L}$ \\
5 & Konduktivitas & 180 & $\mu \mathrm{s} / \mathrm{cm}$ \\
\hline
\end{tabular}

Penurunan kadar COD air sungai oleh karbon aktif yang paling optimal dapat diketahui dengan memvariasikan $\mathrm{pH}$, waktu kontak, dan dosis adsorben. Grafik pengaruh $\mathrm{pH}$ terhadap kapasitas adsorpsi dan efisiensi penyisihan kandungan COD air sungai dapat dilihat pada Gambar 1. 


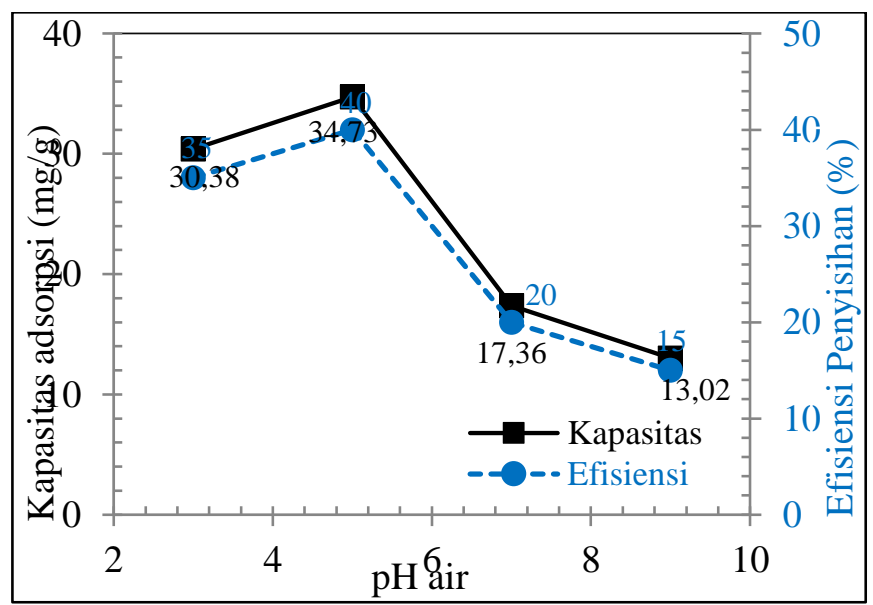

Gambar 1 Pengaruh Variasi pH terhadap Kapasitas Adsorpsi dan Efisiensi Penyisihan COD Air Sungai pada Kondisi $\mathrm{Co}=69,45 \mathrm{mg} / \mathrm{L}$, dosis 0,8 gr/L dan waktu kontak 240 menit

Pada Gambar 1 menunjukkan pH paling optimum dalam menurunkan kadar COD air sungai adalah pH 5 dengan efisiensi adsorpsi sebesar 40\%, sedangkan efisiensi adsorpsi terendah terjadi pada pH 9, yaitu sebesar 15\%. Kapasitas adsorpsi pada pH 3 sebesar 30,38 mg/g dan mengalami peningkatan menjadi $34,73 \mathrm{mg} / \mathrm{g}$ pada $\mathrm{pH}$ 5. Hal ini menunjukkan proses penyerapan ion pada $\mathrm{pH}$ asam adalah rendah. Kondisi pada $\mathrm{pH}$ rendah berarti permukaan karbon aktif dikelilingi oleh ion $\mathrm{H}^{+}$, sehingga terdapat reaksi tolakmenolak antara adsorbat terhadap permukaan adsorben dan menyebabkan proses adsorpsi menjadi tidak optimal. Kapasitas adsorpsi pada $\mathrm{pH} 7$ dan 9 mengalami penurunan, yaitu dari 34,73 mg/g pada pH 5 menjadi 17,36 mg/g pada $\mathrm{pH} 7$ dan terus menurun pada $\mathrm{pH} 9$ sebesar 13,02 mg/g. Efisiensi penyerapan adsorbat pada $\mathrm{pH}$ netral menuju basa akan menurun. Adsorbat akan mengalami reaksi hidrolisis dalam larutan ketika kondisi pH netral, sehingga menyebabkan reaksi tidak stabil dan menurunkan kemampuan karbon aktif dalam mengadsorpsi, sedangkan adsorbat akan membentuk endapan hidroksida pada kondisi basa atau $\mathrm{pH}$ basa, sehingga proses adsorpsi sulit terjadi (Nurafriyanti et al., 2017).

Waktu kontak berkaitan dengan jumlah adsorbat yang teradsorpsi. Kemampuan adsorben dalam mengadsorpsi mempengaruhi waktu kesetimbangan yang akan dicapai (Miryanti \& Witono, 2015). Grafik hubungan variasi waktu kontak terhadap kapasitas adsorpsi serta efisiensi penurunannya diuraikan pada Gambar 2. 


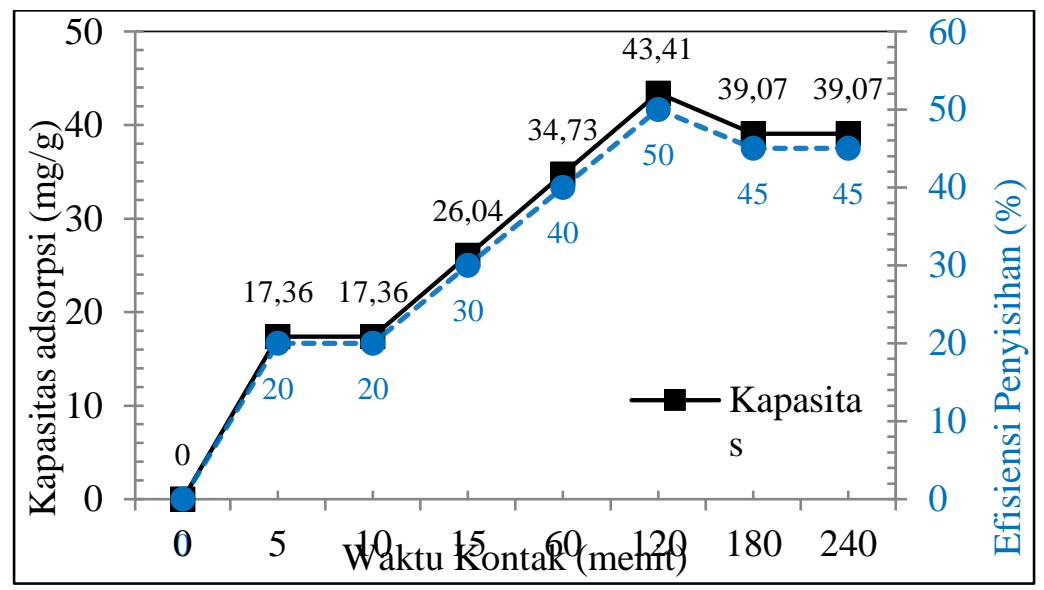

Gambar 2 Pengaruh Variasi Waktu Kontak terhadap Kapasitas Adsorpsi dan Efisiensi Penyisihan COD Air Sungai pada Kondisi Co=69,45 mg/L, pH 5 dan dosis 0,8 gr/L

Berdasarkan Gambar 2 dihasilkan bahwa pada waktu kontak 120 menit didapatkan kapasitas adsorpsi terbesar yaitu 43,41 mg/g dengan efisiensi adsorpsi sebesar 50\%, sedangkan kapasitas adsorpsi terendah terdapat pada waktu kontak 5 dan 10 menit yang menghasilkan kapasitas adsorpsi sebesar 17,36 mg/g dan efisiensi sebesar 20\%. Peningkatan adsorpsi yang terjadi dari menit ke-15 hingga ke-120 menunjukkan seluruh permukaan pori masih kosong dan adsorbat menempel pada permukaan hingga membentuk lapisan. Hal ini menyebabkan laju adsorpsi berlangsung cepat. Pada menit ke-120 hingga ke-360 terjadi penurunan kemampuan adsorben dalam menyerap adsorbat. Hal ini menujukkan adsorben telah mencapai waktu kontak optimum, sehingga ketika waktu kontak melebihi waktu optimum terjadi proses desorpsi. Desorpsi terjadi akibat ketersediaan permukaan adsorben mulai berkurang karena keberadaan adsorbat yang melapisi permukaan adsorben sehingga posri-pori adsorben tertutupi (Aisyahlika et al., 2018).

Dosis adsorben dapat mempengaruhi kontak antara adsorbat dan permukaan adsorben. Analisis kemampuan adsorpsi pada variasi dosis dilakukan pada $\mathrm{pH}$ dan waktu kontak optimal. Grafik hubungan variasi dosis terhadap kapasitas adsorpsi serta efisiensi adsorpsinya diilustrasikan pada Gambar 3. 


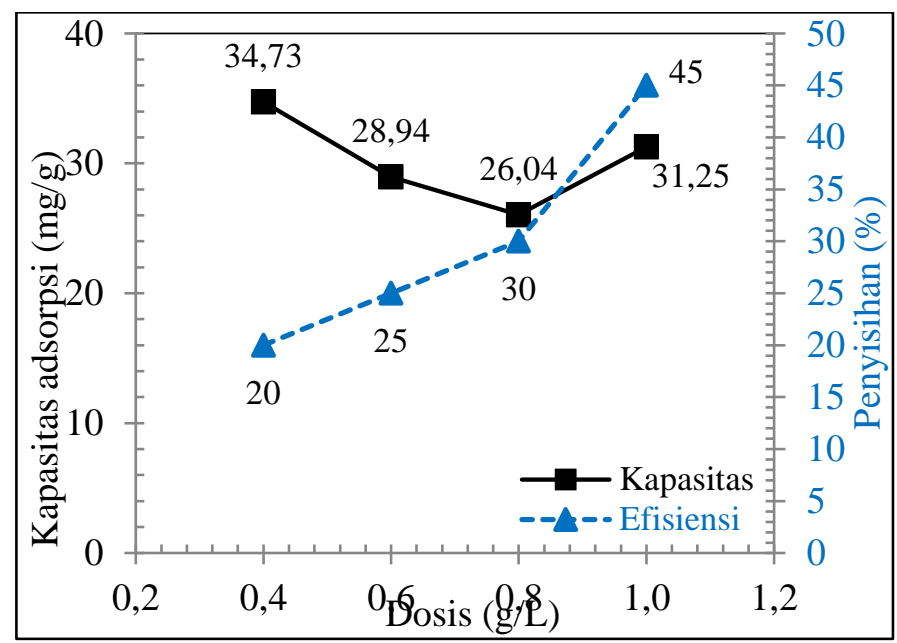

Gambar 3 Pengaruh Variasi Dosis terhadap Kapasitas Adsorpsi dan Efisiensi Penyisihan COD Air Sungai pada Kondisi $\mathrm{Co}=69,45 \mathrm{mg} / \mathrm{L}$, pH 5 dan waktu kontak 120 menit

Pada Gambar 3 memperlihatkan kapasitas adsorpsi terbesar adalah dosis 0,4 gr dengan nilai 34,73 mg/g, sedangkan pada efisiensi tertinggi kapasitas adsorpsi yaitu 31,25 mg/g pada dosis 1 gram. Kapasitas adsorpsi berbanding terbalik dengan efisiensi penyisihan. Meningkatnya dosis adsorben menghasilkan proporsi adsorbat berkurang yang berhubungan dengan jumlah sisi aktif pada permukaan adsorben, sisi aktif tersebut menjadi tidak jenuh sehingga menyebabkan kapasitas adsorpsi menurun. Jumlah adsorben yang berlebihan dapat menyebabkan penurunan kemampuan adsorpsi arang aktif atau desorpsi. Sisi aktif adsorben yang telah dipenuhi oleh gumpalan-gumpalan adsorbat mempersempit luas permukaan dari arang aktif tersebut. Pada Gambar 3 menunjukkan peningkatan efisiensi seiring dengan pertambahan dosis karbon aktif kayu ulin. Peningkatan tersebut berhubungan dengan banyaknya sisi aktif yang tersedia pada permukaan adsorben untuk mengikat adsorbat. Semakin banyak sisi aktif yang tersedia maka kontak antara adsorben dan adsorbat semakin besar, sehingga persentase adsorpsi meningkat (Hidayati et al., 2016).

\section{KESIMPULAN}

Simpulan dari penelitian yang dilakukan adalah:

4.1 Karakteristik adsorben karbon aktif kayu ulin setelah diaktivasi fisika dengan kondisi bertekanan yaitu kadar air sebesar $5 \%$, daya serap iodin sebesar 190,350 mg/g, dan kadar abu sebesar 89\%.

4.2 Kondisi operasi terbaik adsorpsi COD (Chemical Oxygen Demand) pada air sungai terhadap karbon aktif kayu ulin yaitu terdapat pada kondisi:

a. pH 5 (kapasitas adsorpsi 34,73 $\mathrm{mg} / \mathrm{g}$; efesiensi adsorpsi 40\%)

b. waktu kontak adsorpsi 120 menit (kapasitas adsorpsi 43,41 mg/g; efesiensi adsorpsi 50\%)

c. dosis adsorben sebanyak 1 gram dengan kapasitas adsorpsi sebesar 27,78 mg/g dan efesiensi adsorpsi sebesar $40 \%$. 


\section{UCAPAN TERIMAKASIH}

Penulis mengucapkan terimakasih kepada dosen pembimbing bapak Rijali Noor, ST., MT. dan bapak Dr. H. Mahmud, ST., MT. serta kepada orang tua dan rekan-rekan yang telah membantu dalam proses penyelesaian tugas akhir ini.

\section{DAFTAR PUSTAKA}

Aisyahlika, S. Z., Firdaus, M. L. and Elvia, R. (2018) 'Kapasitas Adsorpsi Aarang Aktif Cangkang Bintaro (Cerbera odollam) Terhadap Zat Warna Sintesis Reactive RED-120 Dan Reactive BLUE-198', Jurnal Pendidikan Dan Ilmu Kimia, 2(2), hal. 148-155.

Badan Standar Nasional (1995) SNI 06-3730-1995: Arang Aktif Teknis. Indonesia.

Badariah, B. (2013) Isolasi Alkaloid Bersifat Antimakan Pada Kayu Bulian (Eusideroxylon zwageri T et $B)$. Universitas Lampung.

Hidayati, P., Ulfin, I. and Juwono, H. (2016) 'Adsorpsi Zat Warna Remazol Brilliant Blue R Menggunakan Nata de coco: Optimasi Dosis Adsorben dan Waktu Kontak', Jurnal Sains dan Seni ITS, 5(2), hal. 134-136.

Ibrahim, Martin, A. and Nasruddin (2015) 'Pembuatan dan karaktrisasi karbon aktif berbahan dasar cangkang sawit dengan metode aktivasi fisika menggunakan rotary autoclave', Jom Fteknik, 1(2), hal. 1-11.

Laos, L. E., Masturi, M. and Yulianti, I. (2016) 'Pengaruh Suhu Aktivasi Terhadap Daya Serap Karbon Aktif Kulit Kemiri', in Prosiding Seminar Nasional Fisika, hal. 15-140.

Laos, L. E. and Selan, A. (2016) 'Pemanfaatan Kulit Singkong Sebagai Bahan Baku Karbon Aktif', Jurnal Ilmu Pendidikan Fisika, 1(1), hal. 32-36.

Matilda, F. et al. (2016) 'Peningkatan Kualitas Efluen Limbah Cair Industri Tahu Pada Sistem Lumpur Aktif Dengan Variasi Laju Alir Menggunakan Arang Aktif Kayu Ulin (Eusideroxylon zwageri)', EnviroScienteae, 12(3), hal. 207.

Mirwan, A., Pratidina, N. N. and Sari, A. P. (2019) 'The Utilized Of Ulin Wood Waste (Eusideroxylon Zwageri T) As Active Charcoal To Adsorb Iron (Fe) And Manganese (Mn)', Konversi, 7(1), pp. 15.

Miryanti and Witono (2015) 'Pengembangan Adsorben Activated Fly Ash untuk Reduksi Ion $\mathrm{Cu}$ dan $\mathrm{Cr}$ dalam Limbah Cair Industri Tekstil.', Universitas Katolik Parahyangan.

Nayl, A. E. A. et al. (2017) 'Adsorption studies on the removal of COD and BOD from treated sewage using activated carbon prepared from date palm waste'. Environmental Science and Pollution Research.

Ningrum, S. O. (2018) 'Analisis Kualitas Badan Air Dan Kualitas Air Sumur Di Sekitar Pabrik Gula Rejo Agung Baru Kota Madiun', Jurnal Kesehatan Lingkungan, 10(1), hal. 1-12.

Nurafriyanti, N., Prihatini, N. S. and Syauqiah, I. (2017) 'Pengaruh Variasi pH Dan Berat Adsorben Dalam Pengurangan Konsentrasi Cr Total Pada Limbah Artifisial Menggunakan Adsorben Ampas Daun Teh', Jukung (Jurnal Teknik Lingkungan), 3(1), hal. 56-65.

Rosli, M. A. et al. (2018) 'Adsorption efficiency and isotherms of COD and color using Limestone and zeolite adsorbents', International Journal of Integrated Engineering, 10(8), pp. 8-13.

Valand, S., Singh, D. and Shah, S. (2019) 'Adsorption Study for Removal of COD from Waste Water Using Sustainable Adsorbent : Experimental and Modelling', 2(7), pp. 111-116. 